\title{
BMJ Open Long-term time trends in incidence, survival and mortality of lymphomas by subtype among adults in Manitoba, Canada: a population-based study using cancer registry data
}

Xibiao Ye, ${ }^{1,2}$ Salaheddin Mahmud, ${ }^{1,2}$ Pamela Skrabek, ${ }^{3}$ Lisa Lix, ${ }^{1,2}$ James B Johnston ${ }^{3}$

To cite: Ye X, Mahmud S, Skrabek $\mathrm{P}$, et al. Long-term time trends in incidence, survival and mortality of lymphomas by subtype among adults in Manitoba, Canada: a population-based study using cancer registry data. BMJ Open 2017;7:e015106. doi:10.1136/ bmjopen-2016-015106

- Prepublication history and additional material are available. To view these files please visit the journal online (http://dx.doi.org/ 10.1136/ bmjopen-2016-015106)

Received 10 November 2016 Revised 13 March 2017 Accepted 31 March 2017

CrossMark

${ }^{1}$ Department of Community Health Sciences, University of Manitoba, Winnipeg, Manitoba, Canada

${ }^{2}$ George and Fay Yee Centre for Healthcare Innovation, University of Manitoba, Winnipeg,

Manitoba, Canada

${ }^{3}$ Department of Medical Oncology, CancerCare Manitoba, Winnipeg, Manitoba, Canada

Correspondence to Dr Xibiao Ye; xibiao.ye@gmail. com

\section{ABSTRACT}

Objective To examine 30-year time trends in incidence, survival and mortality of lymphomas by subtype in Manitoba, Canada.

Methods Lymphoma cases diagnosed between 1984 and 2013 were classified according to the 2008 WHO classification system for lymphoid neoplasms. Death data (1984-2014) were obtained from the Manitoba Vital Statistics Agency. To examine time trends in incidence and mortality, we used joinpoint regression to estimate annual percentage change and average annual percentage change. Age-period-cohort modelling was conducted to measure the effects of age, period and cohort on incidence and mortality time trends. We estimated age-specific and standardised 5-year relative survival and used Poisson regression model to test time trends in relative survival.

Results Total Hodgkin lymphoma $(\mathrm{HL})$ incidence in men and women was stable during the study period. Age-standardised total non-Hodgkin lymphoma (NHL) incidence increased by $4 \%$ annually until around 2000 , and the trend varied by sex and NHL subtype. Total HL mortality continuously declined (by $2.5 \%$ annually in men and by $2.7 \%$ annually in women), while total NHL mortality increased (by $4.4 \%$ annually in men until 1998 and by $3.2 \%$ annually in women until 2001) and then declined (by 3.6\% annually in men and by $2.5 \%$ annually in women). Age-standardised 5 -year relative survival for $\mathrm{HL}$ improved from $72.6 \%$ in 1984-1993 to $85.8 \%$ in $2004-2013$, and for NHL from $57.0 \%$ in 1984-1993 to $67.5 \%$ in 2004-2013. Survival improvement was also noted for NHL subtypes, although the extent varied, with the greatest improvement for follicular lymphoma (from $65.3 \%$ in $1984-1993$ to $87.6 \%$ in 2004-2013).

Conclusions Time trends were generally consistent with those reported in other jurisdictions in total $\mathrm{HL}$ and $\mathrm{NHL}$ incidence, but were unique in incidence for $\mathrm{HL}$ and for $\mathrm{NHL}$ subtypes chronic/small lymphocytic leukaemia/lymphoma, diffuse large B cell lymphoma and follicular lymphoma. Survival improvements and mortality reductions were seen for $\mathrm{HL}$ and $\mathrm{NHL}$ in both sexes.

\section{BACKGROUND}

Lymphomas as a group are one of the most common cancers, but the aetiology for the
Strengths and limitations of this study

- Time trends in cancer incidence, survival and mortality are examined simultaneously in the present study to better reflect the effect of cancer control spectrum.

- Continuous variables for the age, period and cohort were used in age-period-cohort modelling to generate more accurate effect estimation.

- The period method was used to calculate 5-year relative survival.

- Incidence rate for the most recent 2-3 years might have been underestimated due to reporting delay, but the influence is very limited.

two main types, Hodgkin lymphoma (HL) and non-Hodgkin lymphoma (NHL), and their subtypes remain unclear. Overall NHL incidence persistently increased prior to mid-1990s globally. ${ }^{1-4}$ Time trends thereafter diverged (ie, incidence continuously increased in some areas such as Europe ${ }^{56}$ but declined in other $\operatorname{areas}^{26}$ ). HL incidence is relatively stable but geographical differences were also observed in temporal trends. ${ }^{7}$ Due to the changes in lymphoma diagnosis and classification, one challenge in interpreting the time trends is distinguishing the real changes in disease occurrence from artefacts caused by changes in these factors over time. The evidence for aetiological heterogeneity among lymphoma subtypes ${ }^{3}$ 8-10 supports the importance of examining time trends by subtype.

HL and NHL had different temporal trends in mortality in past decades. While HL mortality has declined steadily since the $1960 \mathrm{~s},{ }^{2} 1112$ NHL mortality increased prior to the mid-1990s but declined thereafter. ${ }^{212-14}$ Relative survival, defined as the ratio between 
the observed survival in patients with cancer and the expected survival of a comparable group from the general population (assumed to be free of the cancer of interest ${ }^{15}$ ), is increasingly used in population-based cancer survival analysis. ${ }^{16}$ Unlike cause-specific mortality, relative survival does not require information on cause of death as it measures the excess mortality among patients with cancer, irrespective of whether the excess mortality is attributable to the cancer directly or indirectly (eg, deaths due to treatment complication or suicide). Previous relative survival analyses of patients with lymphoma have demonstrated improvement over time, ${ }^{17-21}$ although the extent of improvement varied by patient sociodemographics (eg, gender, age at diagnosis, socioeconomic status, remoteness of residence ${ }^{22-24}$ ) and by lymphoma characteristics (eg, subtype ${ }^{21}$ ).

However, there remains a number of knowledge gaps. First, epidemiological patterns for specific lymphoma subtypes are less clear. Second, incidence, mortality and survival are usually interpreted separately, but the progress against cancer relies on multiple components of cancer control spectrum, including prevention, diagnosis, treatment and supportive care. It is therefore more valuable to simultaneously study trends in incidence, mortality and survival. This combined approach is useful to understand the independent impact of the cancer control measures and their interactions on increased survival. ${ }^{7}$ In this study we examined 30-year time trends in incidence, mortality and relative survival for lymphoid malignancies in adults in Manitoba, Canada.

\section{METHODS AND MATERIALS \\ Data sources}

Cancer diagnosis information was retrieved from the Manitoba Cancer Registry (MCR), a population-based registry operated by CancerCare Manitoba (CCMB). Reporting of cancer cases to the MCR is mandatory and is regularly audited by the North American Association of Central Cancer Registries. ${ }^{25}$ The quality of registry data has been consistently very high. Most cases are pathologically confirmed (94\% for cases registered between 2006 and 2010) and less than $2 \%$ of registrations originate from death certificates. ${ }^{25}$

Histology and topography codes were used to identify lymphoma cases diagnosed between 1984 and 2013 (see online supplementary table 1). Cancer diagnoses were originally coded using earlier editions of the International Classification of Disease for Oncology (ICD-O) and were converted to the 3 rd edition (ICD-O-3).${ }^{26}$ The 2008 WHO classification of lymphoid neoplasms was applied to classify patients according to disease subtype ${ }^{27}$ Other patient characteristics, including sex, birthday, date of diagnosis and residential postal code at the time of diagnosis, were also obtained from the MCR. Household income quintile at diagnosis was determined based on dissemination area level average household income derived from Canadian Census data. ${ }^{28}$ Manitoba population counts by age, sex and year, which were used to calculate incidence and mortality rates, were obtained from the Manitoba Health Insurance Registry. Vital statistics data (1984-2014) were obtained from the Manitoba Vital Statistics Agency. Underlying causes of death were coded using ICD-10 for deaths occurring since 1 January 2000 and using ICD-8/9 for deaths prior to 2000 (see online supplementary table 2). This research has been approved by the University of Manitoba Research Ethics Board, Manitoba Health Information Privacy Committee of Manitoba Health and CCMB Research Resource Impact Committee.

\section{Statistical analysis}

Age-standardised incidence and mortality rates were calculated using the 2006 population of Canada from Canadian Census as the standard population. Time trends were tested for total HL, total NHL and the four most common NHL subtypes (chronic lymphocytic leukaemia/lymphoma (CLL/SLL), diffuse large B cell lymphoma (DLBCL), follicular lymphoma (FL) and plasma cell neoplasms (PCN)) but not other subtypes due to small numbers. We used joinpoint regression (log linear) to test time trends in incidence and mortality. ${ }^{29}$ We first tested the trend with no joinpoint (ie, linear model) and then determined whether more joinpoints (up to 3) need to be added, based on permutation testing and the Bayesian information criterion. ${ }^{29}$ Estimated annual percentage change (EAPC) and 95\% confidence intervals (CIs) were estimated for each time period, and the average annual percentage change (AAPC) for the full observation periods (1984-2013 for incidence and 1984-2014 for mortality) was also calculated. ${ }^{29}$ Joinpoint analyses were conducted using the Joinpoint Trend Analysis Software developed by the National Cancer Institute in the USA (https://surveillance.cancer.gov/joinpoint/).

To examine the effects of age, year of birth (cohort) and year of diagnosis (period) on incidence and mortality rates, we performed age-period-cohort (APC) analyses using the Epi package for $\mathrm{R} \cdot{ }^{30}$ Instead of using fixed intervals (eg, 5-year intervals), we fitted the models using continuous variables for the age, period and cohort through the use of restricted cubic spline functions, as recommended by Carstensen. ${ }^{30}$ Matrix transformations were made to the spline basis vectors for the period and cohort effects to overcome the wellknown identifiability problem in APC modelling. ${ }^{30}$ We graphically present age-specific incidence/mortality rate after adjusting for the effects of cohort and period. We used rate ratio to measure cohort and period effects on the age-standardised rates. The cohort rate ratio, the ratio of incidence/mortality rate in a given year of birth versus the rate in a reference cohort (ie, the central 1931 birth cohort), describes the relative risk after taking into account age and period effects, whereas the period rate ratio is the ratio of incidence/mortality rate in a given year of diagnosis versus the rate in a reference period (ie, the central 2001 year of diagnosis) and describes the relative risk after taking into account age and cohort effects. 
We estimated 5-year relative survival, the ratio between observed survival of patients with lymphoma and the expected survival of a comparable Canadian general population using the period analysis method. ${ }^{31}$ Expected survival was estimated according to the Ederer II method ${ }^{32}$ using Canadian age-specific and sex-specific mortality by year obtained from the Human Mortality Database (www. mortality.org). Age-specific relative survival ratios were estimated for three age groups (20-54, 55-74, 75+ years) by time period (1984-1993, 1994-2003, 2004-2013), and age-standardised relative survival ratios for each time period were calculated using international standard cancer population. ${ }^{33}$ Standard errors for relative survival were estimated using the Greenwood method and $95 \%$ CIs were derived using a logarithmic transformation. ${ }^{34}$

A Poisson regression model was used to test the time trend in 5-year relative survival using the $\mathrm{R}$ package periodR. ${ }^{35}{ }^{36}$ A generalised linear model was first fitted for observed deaths as a function of follow-up year and age category. The logarithm of the number of patients at risk is provided as offset. Time period was then added to the model and a Wald test was performed to test the trend over time (ie, whether the coefficient for time period is different from 0$){ }^{37}$

\section{RESULTS \\ Incidence}

During 1984-2013, 6808 men and 5520 women were diagnosed with lymphoma (table 1). HL and NHL accounted for approximately $6 \%$ (6.1\% in men and 5.8 in women) and nearly $90 \%$ ( $87.7 \%$ in men and $86.6 \%$ in women) of total lymphomas in men, respectively. Lymphoma subtype was not specified for $6.1 \%$ male cases and $7.5 \%$ female cases. About $95 \%$ (94\% in men and $97.5 \%$ in women) of HL cases were classical HL. The four most common NHL subtypes (CLL/SLL, DLBCL, FL and PCN) accounted for more than three-quarters of the total NHL cases. Generally, the median ages of diagnosis for NHL subtypes were younger in men than in women. Overall, men had higher incidence rates for total HL, total NHL and major NHL subtypes (except for FL) than women (table 2).

During 1984-2013, age-standardised incidence rates (per 100000) for total HL ranged between 2.9 and 3.8 in men and between 2.2 and 2.9 in women (table 2), whereas age-standardised incidence rates for total NHL ranged between 32.5 and 58.9 in men and between 24.3 and 43.7 in women. In joinpoint analyses (supplementary figure 1), no statistically significant change in total HL incidence was observed during the study period, but the incidence for total NHL increased by $2.3 \%$ (95\% CI 1.7\% to $2.9 \%$ ) annually in men and by $2.0 \%$ (95\% CI $1.4 \%$ to $2.6 \%$ ) annually in women (table 3 ). The overall trend was driven largely by the increase in earlier years: $4.2 \%$ annual increase (95\% CI $3.2 \%$ to $5.2 \%$ ) in men during $1984-$ 1998 and $4.3 \%$ annual increase (95\% CI $3.3 \%$ to $5.2 \%$ ) in women during 1984-2001. Time trends in incidence varied by NHL subtype: DLBCL incidence increased by about $4 \%$ annually in men (95\% CI $3.1 \%$ to $4.8 \%$ ) and by $4.1 \%$ in women $(95 \%$ CI\% 3.1 to $5.1 \%)$ during $1984-$ 2013; CLL/SLL incidence increased differently in men (EAPC $=1.8 \%, 95 \%$ CI $1.0 \%$ to $2.5 \%$, during $1984-2010$ ) and in women $(\mathrm{EAPC}=3.6 \%, 95 \% \mathrm{CI} 2.3 \%$ to $5.0 \%$, during 1984-2005) in early years, followed by a statistically significant decline $(\mathrm{EAPC}=-7.7 \%, 95 \% \mathrm{CI}-12.4 \%$ to $-2.7 \%$, during 2005-2013) in women and a statistically non-significant decline in men $(\mathrm{EAPC}=-10.1 \%, 95 \% \mathrm{CI}-26.0 \%$ to 9.3\%, during 2010-2013). FL incidence in men increased $3.5 \%$ annually (95\% CI $1.8 \%$ to $5.3 \%$ ) during 1984-2003, but declined by $3.0 \%$ annually (95\% CI $-6.3 \%$ to $0.4 \%$ ) since 2003; FL incidence in women slightly increased (AAPC $=1.0 \%, 95 \% \mathrm{CI}-0.0 \%$ to $2.0 \%$ ). PCN incidence increased by $0.6 \%$ annually in men but remained stable in women.

APC models showed different curves for age-specific incidence rates (ie, age effects). Age-specific incidence rate curves for total $\mathrm{HL}$ in men present an ' $\mathrm{M}$ ' shape (in particular for men), that is, there were two peaks of higher rates around age of 25 years and age of 75 years and a lower rate around age of 45 years (figure 1A). No cohort or period effects were found for HL incidence (figure 1A,B). Age-specific incidence rate for total NHL reached the highest at the age of 80-85 years and then declined (figure 1C,D). Cohort-specific trends for NHL incidence varied by sex and subtype. For total NHL, incidence rate in men continuously increased and started to decline among those born after 1940, while the incidence in women continuously increased (figure 1C,D). DLBCL incidence continuously increased in men and women (figure $1 \mathrm{E}, \mathrm{F}$ ). Increases in cohort-specific incidence were also found for CLL/SLL in both sexes and for FL in women prior to birth year 1910, but not for FL in men (figure 1I). Total NHL and CLL/SLL incidence rates in women significantly decreased since around 2005 (figure 1D,H). There were no apparent period-specific trends for other NHL subtypes (figure 1K,L).

\section{Mortality}

During 1984-2014, 153 people (95 men and 58 women) died from HL and 3125 people (1609 men and 1516 women) died from NHL. The median ages at death for HL were 66 years in men and 60 years in women, and for NHL were 73 years in men and 77 years in women. Age-standardised mortality rates for HL (per $100000)$ continuously declined in both sexes: from 1.00 during 1984-1989 to 0.47 during 2010-2014 in men, and from 0.62 during 1984-1989 to 0.29 during 2010-2014 in women (table 4). In joinpoint analysis of HL mortality (see online supplementary figure 2), AAPC was $-2.5 \%(95 \% \mathrm{CI}-4.6 \%$ to $-0.3 \%)$ in men and $-2.7 \%(95 \%$ CI $-5.0 \%$ to $-0.3 \%)$ in women. The time trends in NHL mortality (table 5 and supplementary figure 2) were different from that for HL: total NHL mortality rates increased by $4.4 \%$ annually in men and by $3.2 \%$ annually in women by the end of $1990 \mathrm{~s}$, and declined thereafter in both men (by $3.6 \%$ annually) 


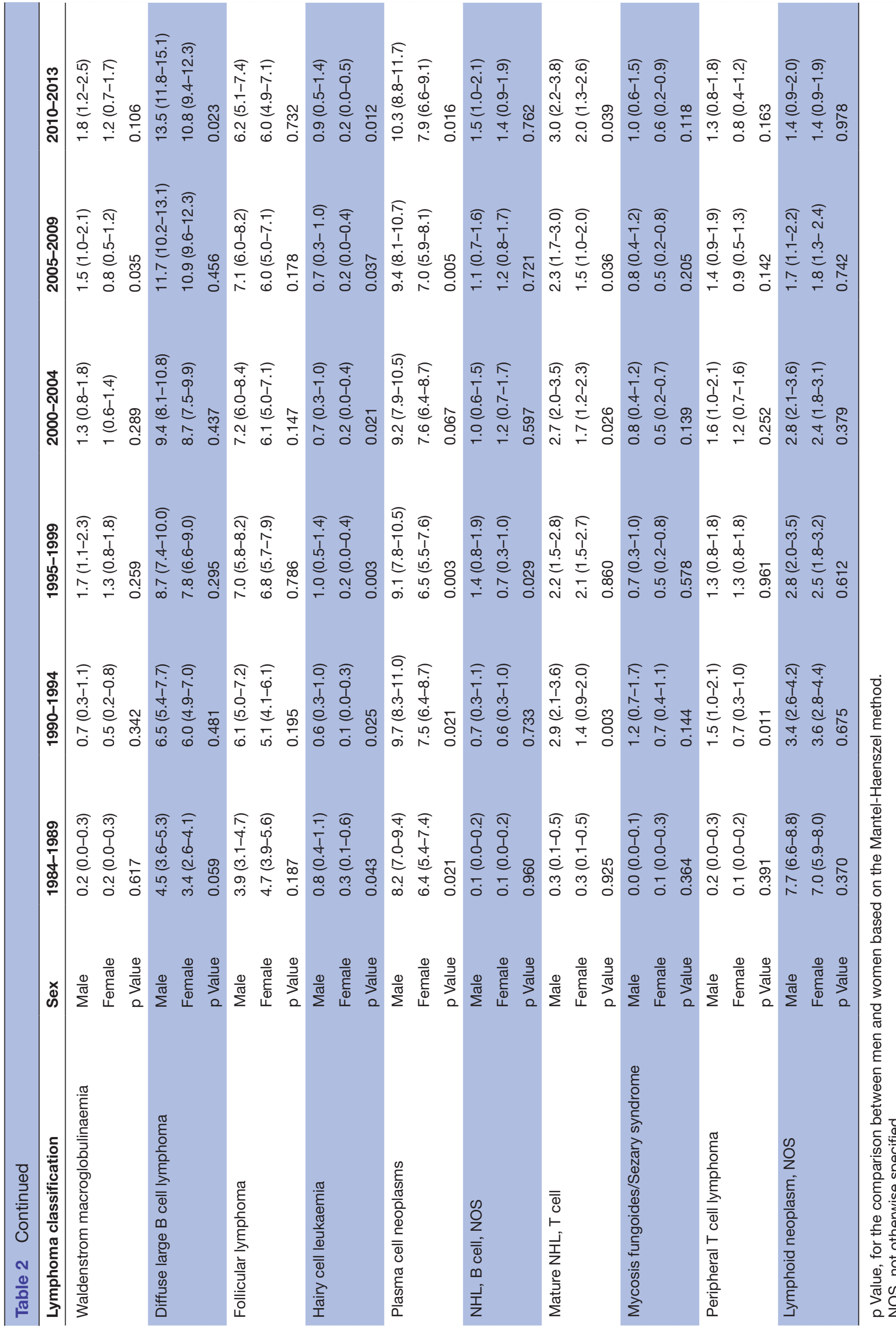




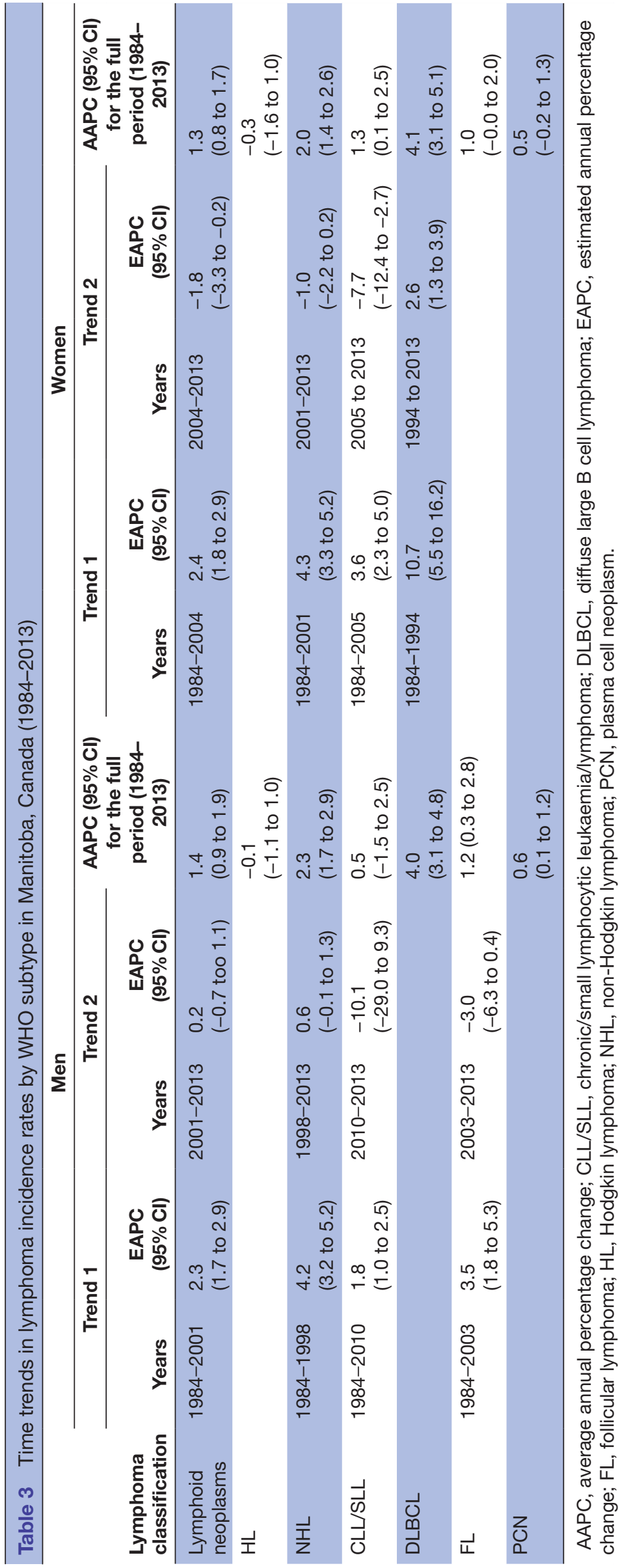

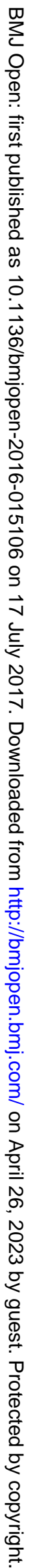


Male

A

HL

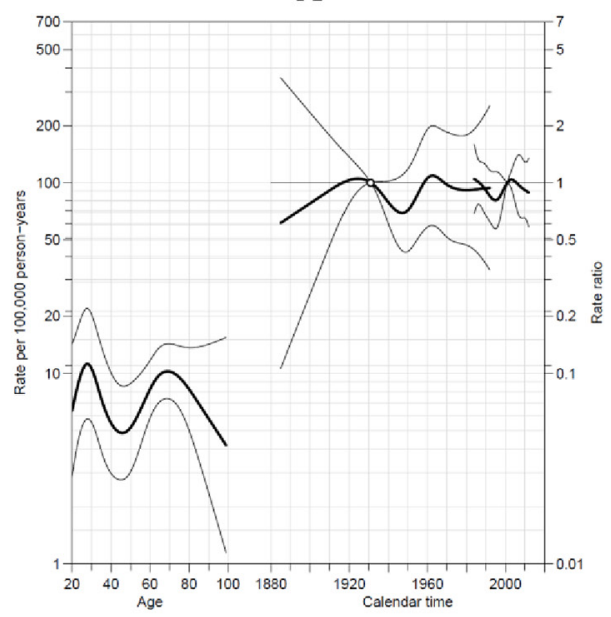

C

NHL

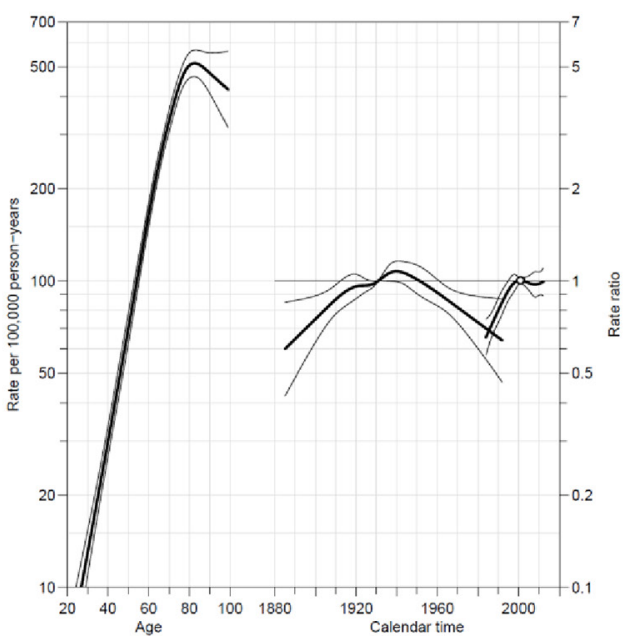

\section{Female}

B

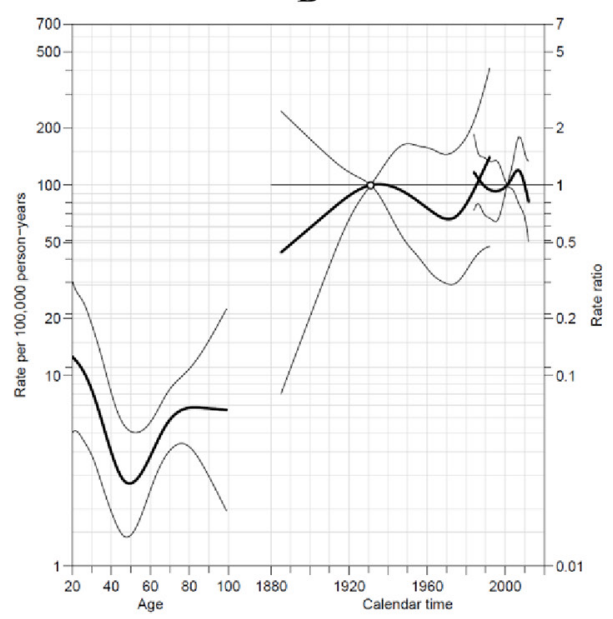

D

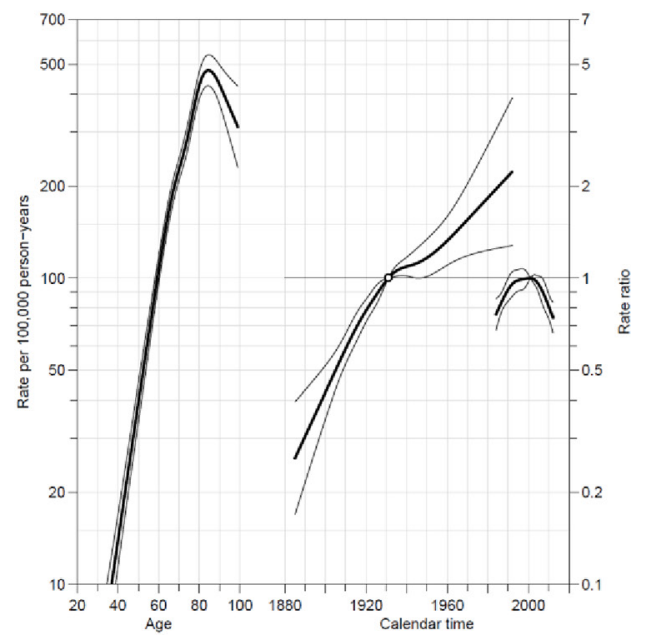

Figure 1 Effects of age, cohort and period on lymphoma incidence time trends in Manitoba, Canada (1984-2013). CLL/SLL, chronic/small lymphocytic leukaemia/lymphoma; DLBCL, diffuse large B cell lymphoma; FL, follicular lymphoma; HL, Hodgkin lymphoma; NHL, non-Hodgkin lymphoma; PCN, plasma cell neoplasms.

and women (by $2.5 \%$ annually). During the peak period (1995-1999), age-standardised mortality for NHL was 16.58 (95\% CI 14.79 to 18.38$)$ in men and $13.71(95 \%$ CI 12.13 to 15.29$)$ in women.

APC models showed no statistically significant effects on HL mortality (figure 2A,B). Total NHL mortality increased with age (figure 2C,D). Declines in age-standardised total NHL mortality started in men born in 1950 and in women born in 1945. Period-specific total NHL mortality rates increased prior to 1995 in men and prior to 1985 in women, but started to decline since 2003 in men and since 2010 in women.

\section{Relative survival}

In both men and women, 5-year relative survival for total HL, total NHL and NHL subtypes decreased with age except for CLL/SLL (table 6), but it was generally higher in women. Changes in relative survival over time varied by sex, age group and subtype. For HL, the oldest group (75+ years) had the best improvement. For CLL/
SLL in men, relative survival has been stable over time in those aged 20-54 years, but significantly improved in the older people, while in women relative survival declined over time for the youngest age group. For FL, relative survival improved for all groups. For PCN, while 5-year survival increased over time in those aged under 75 years, it declined in those aged over 75 years.

After adjusting for age, we found that 5-year relative survival for HL and all NHL subtypes improved over time in both sexes. Trend analysis showed an overall increase in 5-year relative survival for HL and NHL (table 6): from 1984-1993 to 2004-2013, there were $12.3 \%$ unit increase in men and $14.3 \%$ unit increase in women for HL, and $11.7 \%$ unit increase in men and $7.8 \%$ unit increase in women for NHL. Among the four most common NHL subtypes, age-standardised 5-year relative survival in men was the highest for FL (65.3\% in 1984-1993 and $87.6 \%$ in 2004-2013) and the lowest for PCN (32.0\% in 1984-1993 and $39.4 \%$ in 2004-2013). Differential period effects were 
Table 4 Age-standardised mortality rates (per 100000) of lymphomas in Manitoba, Canada (1984-2014)

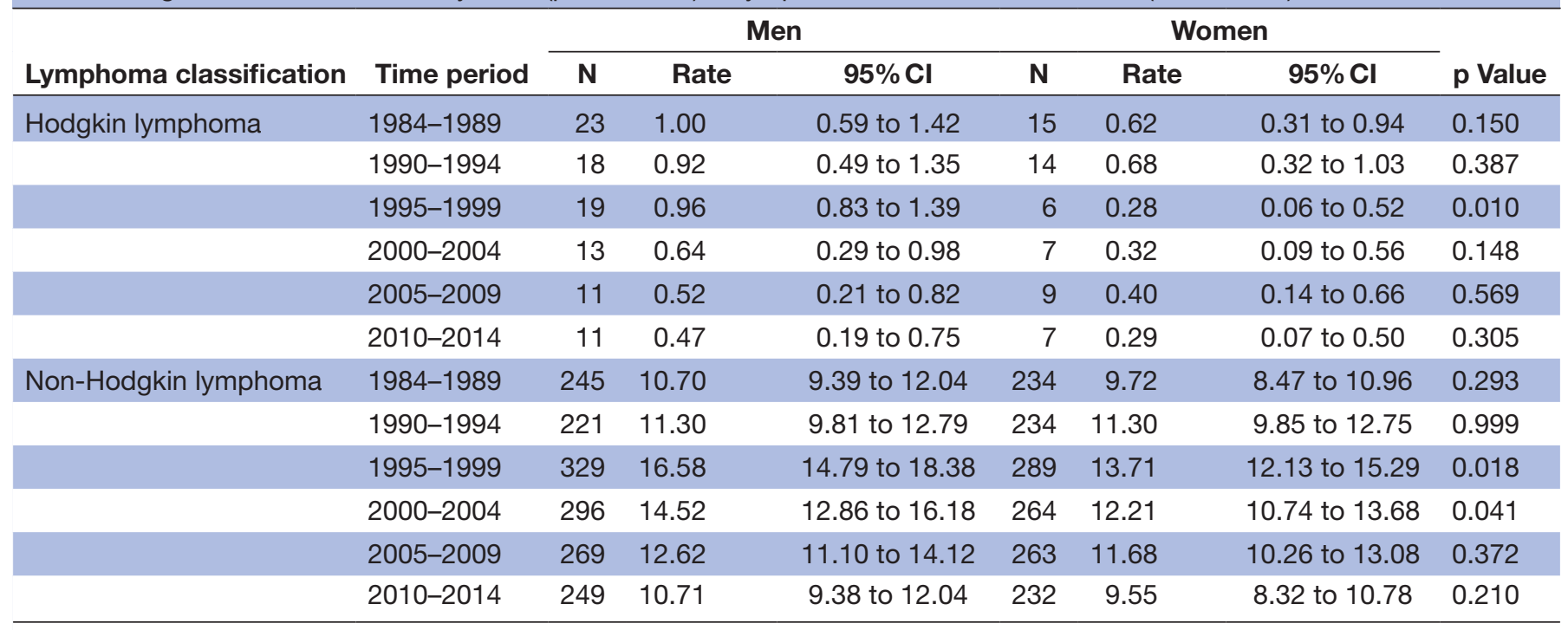

$\mathrm{p}$ Value: for the comparisons between men and women.

found for HL and NHL and major subtypes (see online supplementary table 3). Comparing with 1984-1993, relative excess mortality risk for HL in both sexes was similar in 1994-2003 and 2004-2013; a statistically significant period effect was only seen in 2004-2013. Period effects were observed in 2005-2013 only for NHL subtypes with an exception of CLL/SLL. Statistically significant period effects were found for CLL/SLL in both 1994-2003 and 2004-2013.

\section{DISCUSSION}

We found that total HL incidence was relatively stable between 1984 and 2013 while total NHL incidence increased until around 2000 and then plateaued. While total HL mortality rate continuously declined over time, total NHL mortality rate increased prior to the end of 1990s and declined thereafter. On the other hand, relative survival improved for all lymphomas, although the extent of improvement varied by sex, age group and lymphoma subtype. Important findings are summarised in table 7.

\section{Incidence}

Previous studies have focused on time trends in total HL incidence and total NHL incidence, and there were geographical variations in the trends. ${ }^{14}$ AAPC ranged from $1.3 \%$ to $6.1 \%$ for NHL incidence and from $-2.8 \%$ to $2.6 \%$ for HL incidence across European countries. ${ }^{38}$

Average annual increases in NHL incidence for men and women in the present study were greater than that in the Netherlands. ${ }^{39}$ HL incidence in the present study has been relatively stable, but it decreased in both men $(-1.0 \%$ annually) and women ( $-1.8 \%$ annually) in the USA during 2004-2013 ${ }^{40}$ Little is known about the time trends in incidence of lymphoma subtypes. This study found that time trends in incidence of certain subtypes were different from those reported in previous studies. After a continuous increasing for two decades, CLL/SLL started to decline in 2005. Similar decline was found in the USA between 2004 and 2013. ${ }^{40}$ The reduction in CLL/SLL incidence may be explained by the diagnosis change, that is, individuals who would have been classified as CLL/SLL were classified as monoclonal $\mathrm{B}$ cell lymphocytosis if the absolute $\mathrm{B}$ cell count was $<5 \times 10^{9} / \mathrm{L}{ }^{41}$ For DLBCL, the incidence continuously increased during 1984 and 2014 (by 4\% annually in men and by $2.6 \%$ annually in women). The extent of the increase was in the range of changes reported in other counties. ${ }^{42}$ Different time trends were also found for FL, that is, there were no statistical changes in either sex in the

Table 5 Time trends in age-standardised lymphoma mortality rates in Manitoba, Canada (1984-2014)

\begin{tabular}{|c|c|c|c|c|c|c|}
\hline $\begin{array}{l}\text { Lymphoma } \\
\text { classification }\end{array}$ & Sex & \multicolumn{2}{|c|}{ Trend 1} & \multicolumn{2}{|c|}{ Trend 2} & $\begin{array}{l}\text { AAPC }(95 \% \mathrm{Cl}) \\
\text { for the full period } \\
(1984-2014)\end{array}$ \\
\hline \multirow[t]{2}{*}{ Hodgkin lymphoma } & Male & & & & & $-2.5(-4.6$ to -0.3$)$ \\
\hline & Female & & & & & $-2.7(-5.0$ to -0.3$)$ \\
\hline \multirow[t]{2}{*}{ Non-Hodgkin lymphoma } & Male & 1984-1999 & 4.4 (2.4 to 6.3$)$ & 1999-2014 & $-3.6(-5.3$ to -1.9$)$ & $0.3(-0.9$ to 1.5$)$ \\
\hline & Female & 1984-1998 & $3.2(0.9$ to 5.6$)$ & 1998-2014 & $-2.5(-4.3$ to -0.8$)$ & $0.1(-1.2$ to 1.5$)$ \\
\hline
\end{tabular}

AAPC, average annual percentage change; EAPC, estimated annual percentage change. 
HL

Male

A

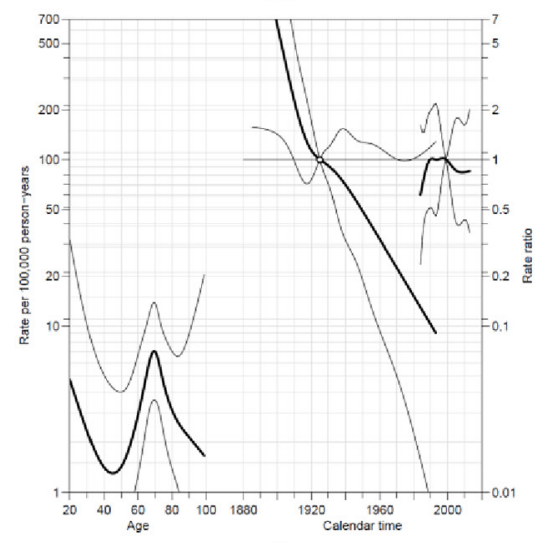

NHL

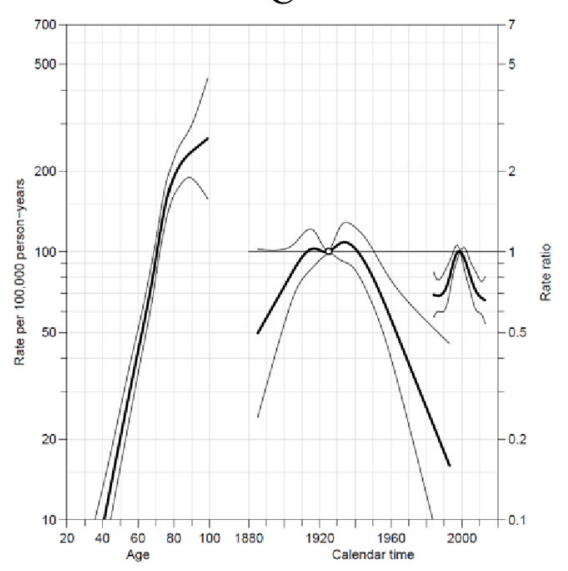

Female

B

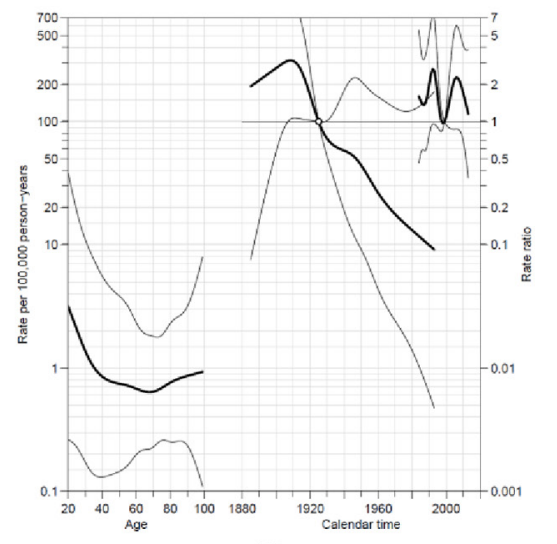

$\mathrm{D}$

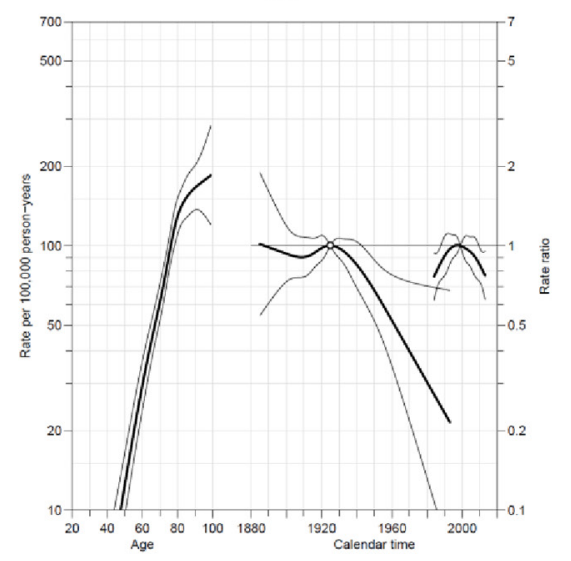

Figure 2 Effects of age, birth cohort and period on lymphoma mortality time trends in Manitoba, Canada (1984-2014). HL, Hodgkin lymphoma; NHL, non-Hodgkin lymphoma. Note: the left vertical axis is a logarithmic rate scale referring to age effects (ie, age-specific incidence rate after adjusting for cohort and period effects). The right vertical axis is a logarithmic rate ratio scale of the same relative extent as the left, referring to the effects of birth cohort (middle) and period (rightmost). The bolded line and the surronding unbolded lines are point estimate and $95 \%$ confidence interval.

present study, while in the same time period FL incidence in the US men and women declined by $2.1 \%$ annually. ${ }^{40}$ PCN incidence increased in men only in the present study and in USA as well. ${ }^{40}$

The aetiology of HL and NHL remains largely unknown. For NHL, there are only a few well-established risk factors, including age, congenital or acquired immunodeficiency disorders such as organ transplantation and HIV, and autoimmune disorders (eg, rheumatoid arthritis) ${ }^{4344}$ Increased cancer incidence could be attributed to population ageing, higher prevalence of risk factors, better screening/diagnosis or improved completeness of cancer registration. In the present study, we found that ageing and factors associated with birth cohort and diagnosis time impacted NHL incidence trends. This confirmed the findings of several previous studies. $\mathrm{Liu}^{45}$ and colleagues found statistically significant period effects on NHL incidence in both sexes, but a cohort effect among women only. Viel $e t$ als analysis suggested that NHL incidence increase in Doubs, France during 1980-2005 was mostly dependent on factors associated with age and time period instead of cohort. ${ }^{46}$ In Spain, factors related to age, cohort and period contributed to the NHL incidence increase during 1973-1991. ${ }^{47}$ The cohort effect may be due to physical and social environmental changes, while the period effect might be partially explained by improved diagnosis, classification and case registration. Lymphoma classification has experienced many changes and might have some impact on time trends of certain subtypes, but the impact on total HL and total NHL might be very limited. ${ }^{6}{ }^{6}$ An earlier study in Manitoba showed a large increase in CLL/SLL incidence during 1998-2003 that was largely related to the introduction of flow cytometer testing but was also due to the misclassification of CD5 positive chronic lymphoproliferative disorders as CLL/SLL. ${ }^{49}$ The changes in diagnosis, registration and known risk factors might partially explain the incidence trends in this study, but the extent of the influence was not quantified. Hartge and Deves ${ }^{50}$ found that improved accuracy and completeness of diagnosis (ie, less NHL cases were misdiagnosed as HL cases), HIV infection and occupational exposures explained around only half of the NHL incidence increase in the USA between 1947-1950 and 1984-1988. 


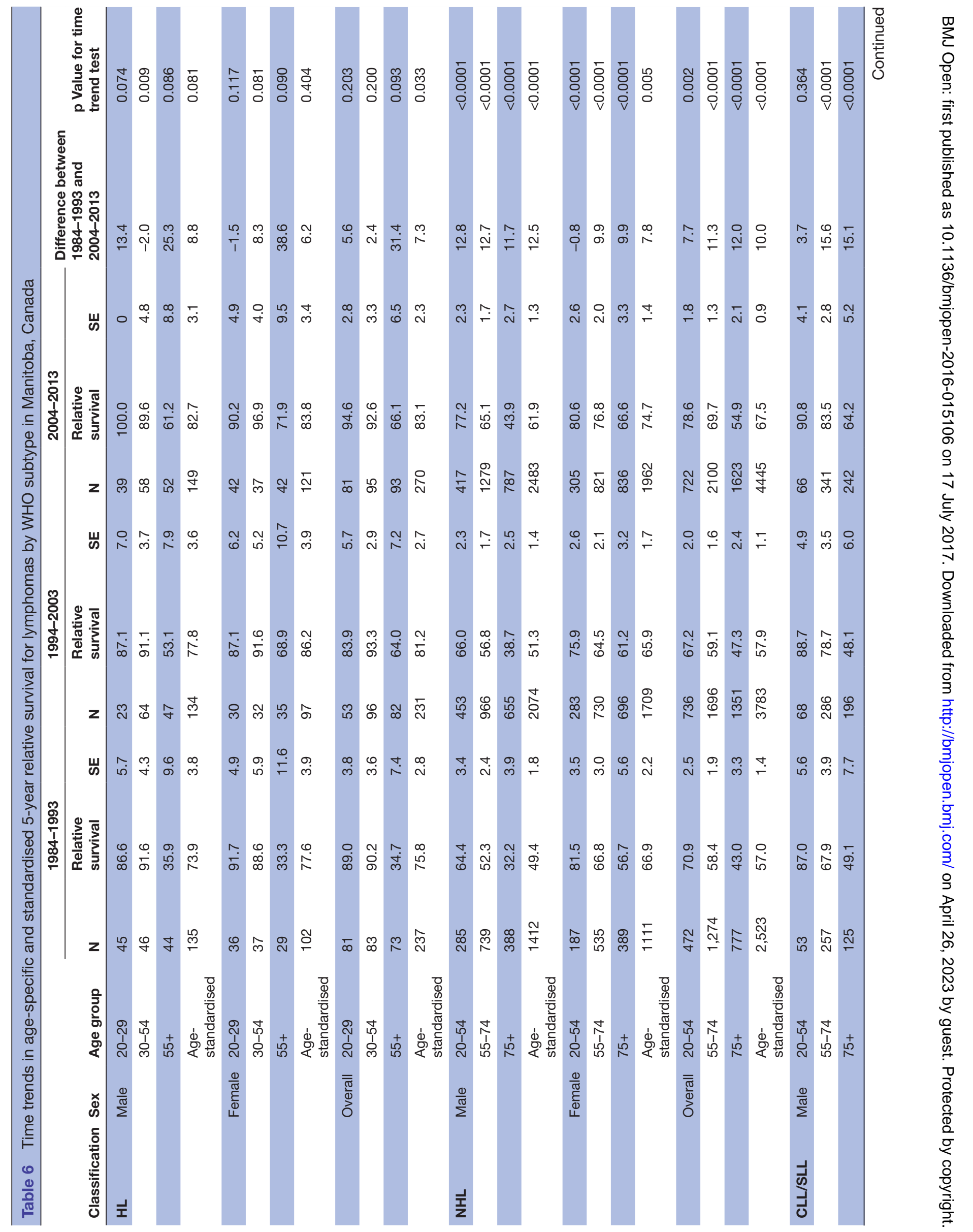




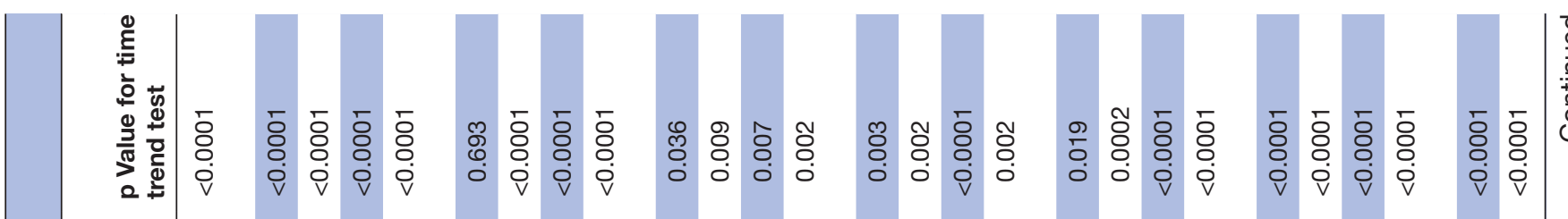

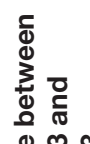

¿ू⿻

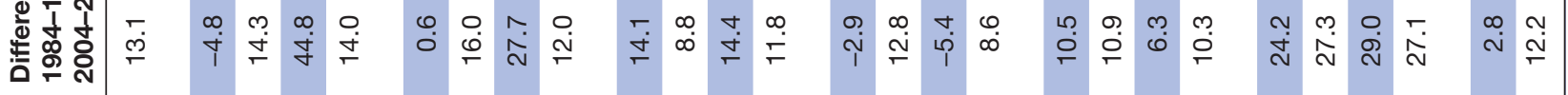

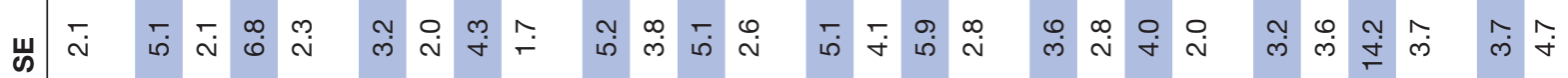

㠃

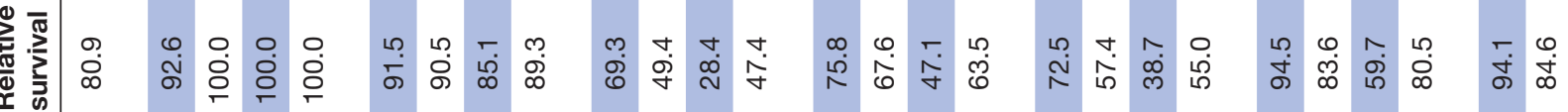

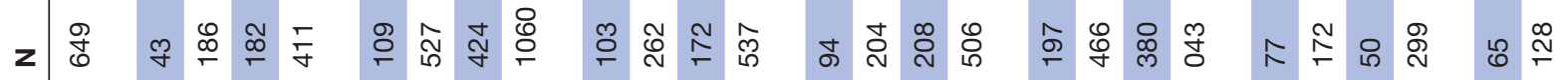

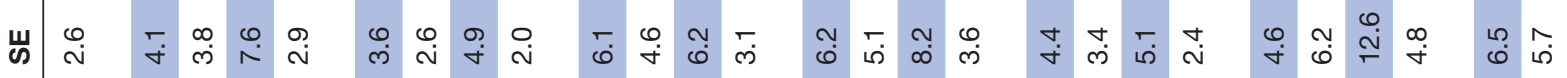

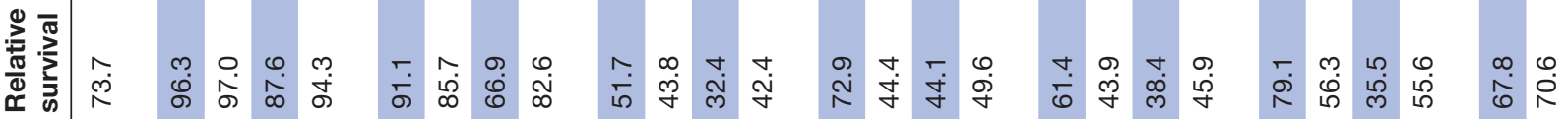

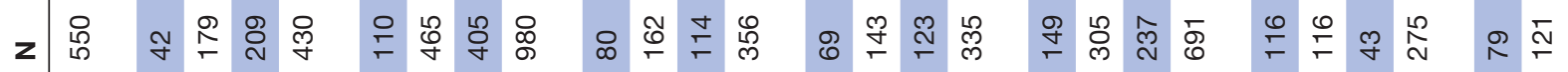

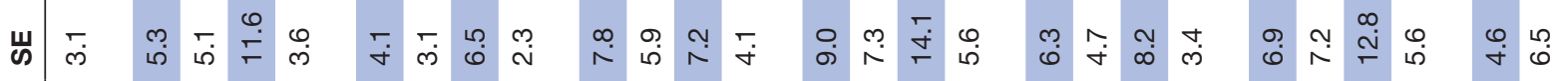

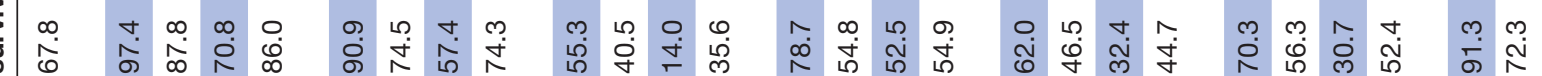

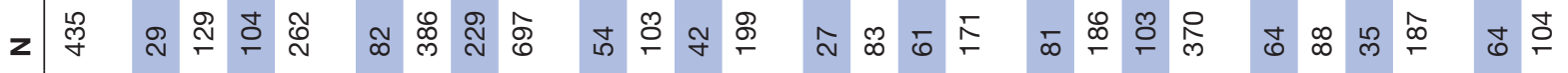

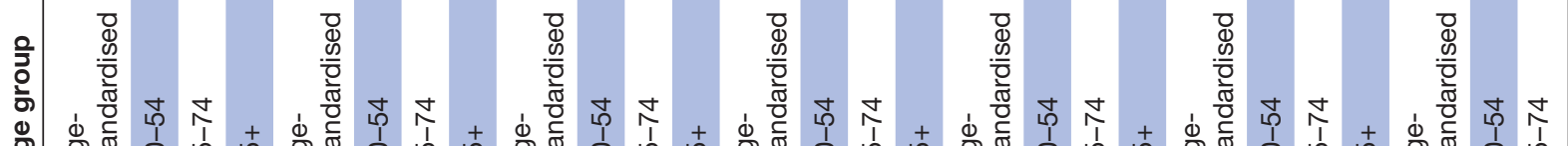

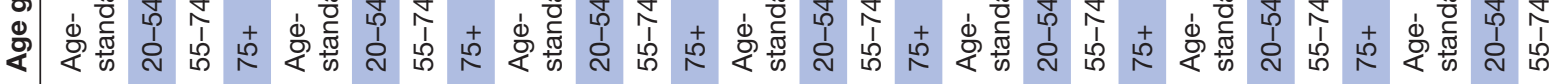
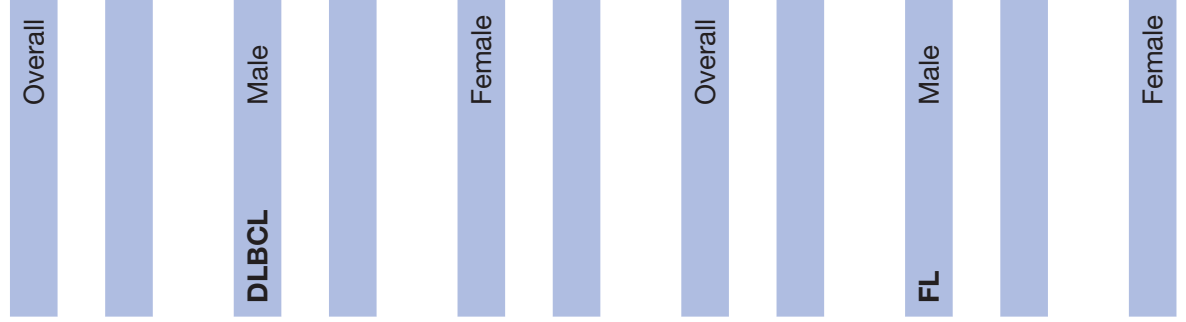


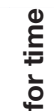

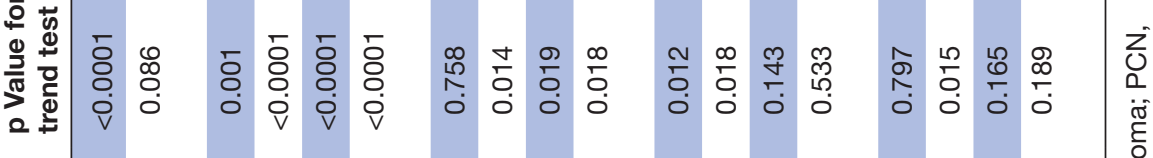

离

이

س

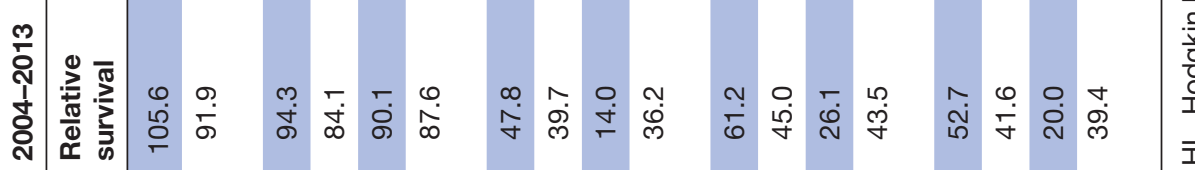

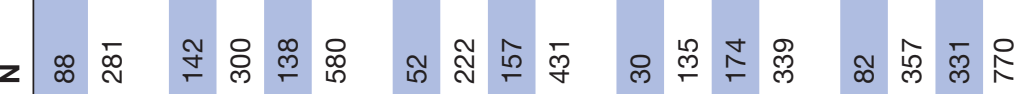

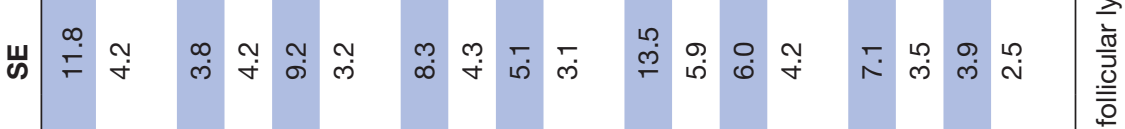

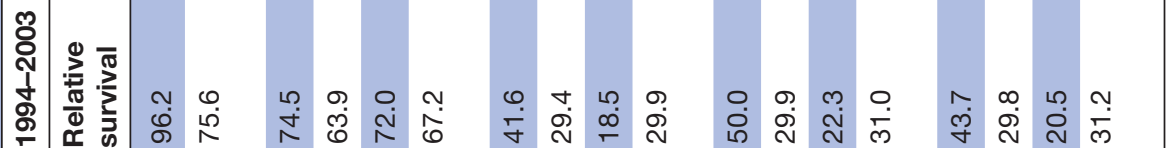

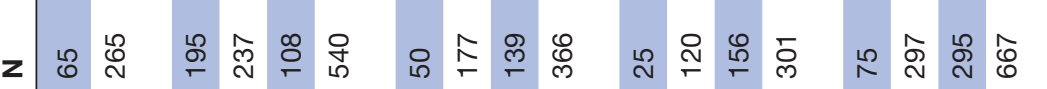

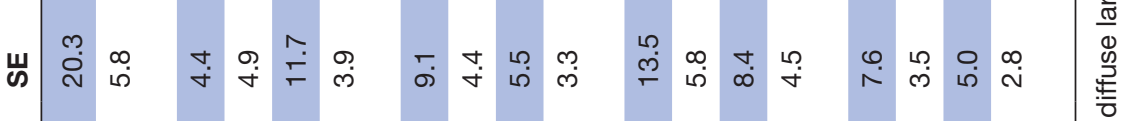

\%

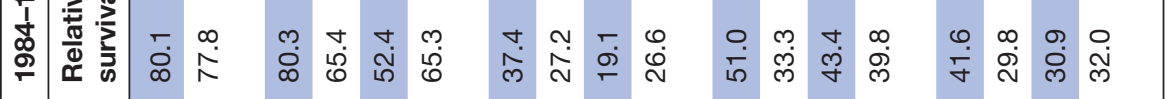

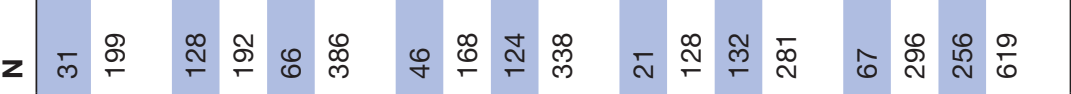

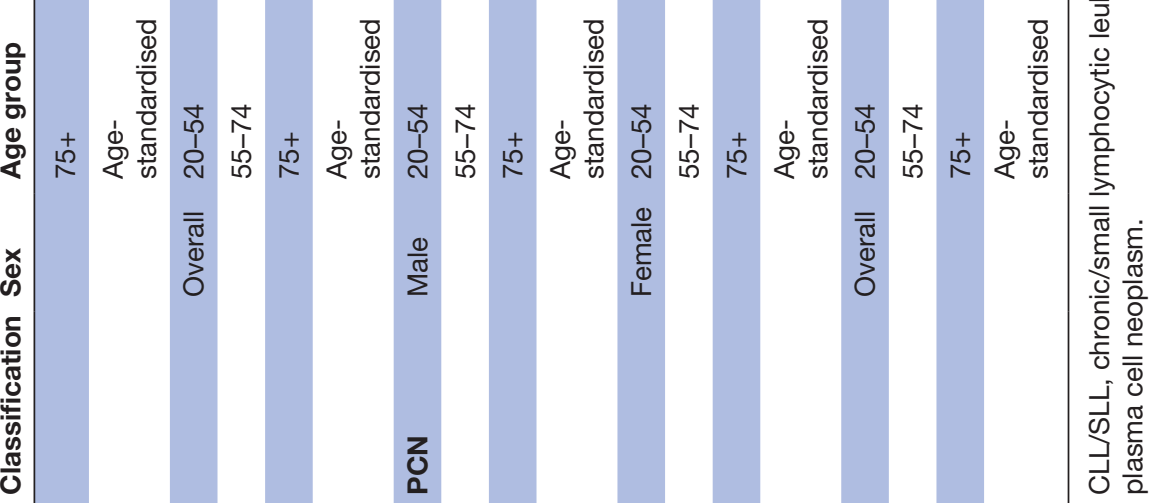


Table 7 Summary of time trends in age-standardised lymphoma incidence, survival and mortality in Manitoba, Canada

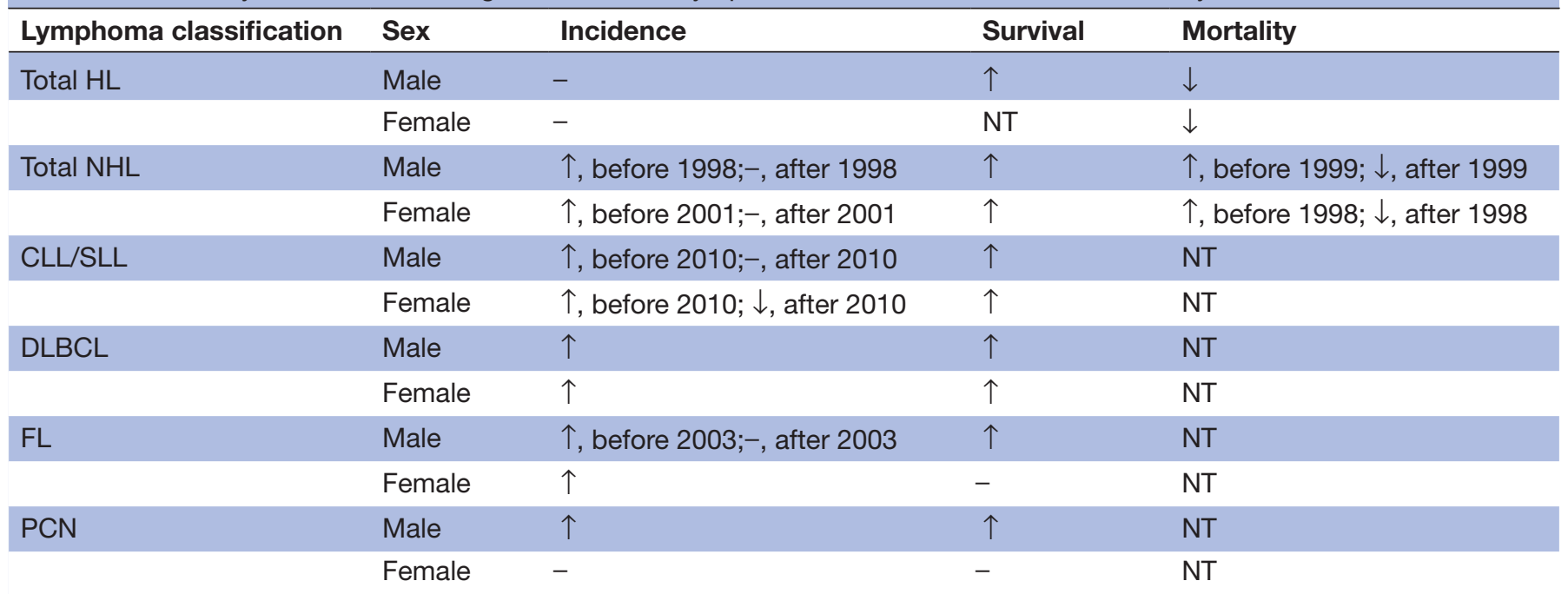

- denotes no change.

CLL/SLL, chronic/small lymphocytic leukaemia/lymphoma; DLBCL, diffuse large B cell lymphoma; FL, follicular lymphoma; HL, Hodgkin lymphoma; NHL, non-Hodgkin lymphoma; NT, not tested; PCN, plasma cell neoplasm.

\section{Survival}

Lymphoma survival in Manitoba improved over time, but generally women had better survival than men, which is consistent with previous findings. ${ }^{17} 5152$ Improvement was greater for older patients with HL ( $\geq 55$ years) than in younger patients, on both absolute and relative measures (ie, absolute increase in relative survival and relative ratio for relative survival). This is consistent with previous study findings. In Sweden, 5-year relative survival for patients with HL aged 19-35 years increased from $72 \%$ in 1973-1979 to 96\% in 2001-2009 (with an absolute increase of $24 \%$ and a relative increase ratio of 1.3 ), but that for patients aged $66-80$ years it increased from $18 \%$ to $44 \%$ (with an absolute increase of $26 \%$ but a relative increase ratio of 2.4$).^{53}$ Another study showed that patients with HL aged 75+ years had a greater improvement, compared with those aged 65-74 years. ${ }^{54}$

In this analysis, 5-year relative survival for NHL improved for all age groups except in women aged 20-54 years. During 1990-2004, 5-year relative survival for total NHL in USA improved across all age groups ( $>15$ years), but the greatest improvement was seen in men aged 15-44 years and women aged $75+$ years. ${ }^{55}$ Similar trends were observed in Western Europe for the same time period, but in Central Europe there were no improvements in older patients. ${ }^{55}$ In Germany, a greater improvement in 5 -year relative survival was observed in patients with NHL aged $85+$ years, compared with those aged 65-74 years. ${ }^{54}$

Lymphoma treatment advances over the past three decades include the introduction of new chemotherapy drugs and monoclonal antibodies (eg, rituximab), autologous stem cell transplantation and optimised radiation therapy to reduce toxicity. ${ }^{56}$ Rituximab was introduced to Europe in 1997 and to Manitoba in 2003. Survival increases were found in the present study and in Europe. ${ }^{57}$ The increase in FL and DLBCL survival varied between European countries, probably associated with the different introduction of rituximab to those countries. As observed in Europe, ${ }^{724}$ there was a smaller increase in age-standardised 5-year relative survival for HL than for NHL in Manitoba. This is likely because there have been no new drugs for HL treatment until the approval of Brentuximab vedotin in $2011 .^{58}$ There was a $10.5 \%$ increase in age-standardised 5-year relative survival for total NHL, which was similar to figures observed for the entire Canadian population where there was a $12 \%$ increase (from $51 \%$ to $63 \%$ ) from 1992-1994 to 2004-2006..$^{20}$ But time trends for NHL subtypes were not presented in this national analysis.

NHL subtype impacts patient survival ${ }^{21}$ and we found that the magnitude of NHL survival improvement over time varied by subtype as well. Our data showed that $22.3 \%$, $12.0 \%$ and $10.3 \%$ increases were found for FL, CLL/SLL and DLBCL in the present study from 1984-1993 to 20042013. Similarly, the highest increase in survival was found for FL in Europe. From 1997-1999 to 2006-2008 in Europe, among all haematological cancer subtypes, the largest increases in age-standardised 5-year relative survival were found for FL (from $58.9 \%$ to $74.3 \%$ ), followed by CLL/ SLL (from $32.3 \%$ to $54.4 \%$ ) and DLBCL (from $42 \%$ to $55.4 \%)^{57}$

\section{Mortality}

Diverse time trends in NHL mortality have been found worldwide, ${ }^{59}$ but the trend (ie, increased between 1984 and late 1990s and declined thereafter) in Manitoba was similar to that observed in USA, Japan and Europe. ${ }^{21160-62}$ Our data suggested an effect of birth cohort on HL mortality among those born prior to $1930 \mathrm{~s}$, but the result needs to be interpreted with caution due to the small number of HL death cases in the analysis. A study from 
Spain showed the effects on both cohort and period on HL mortality and NHL mortality. ${ }^{63}$ The effects of cohort and period on NHL mortality were also identified in the present study. Those effects are likely attributable to the improvement in lymphoma treatment. Lead time bias associated with better diagnostic techniques, for example, flow cytometer, might have also played a role.

\section{Combination of incidence, survival and mortality}

The three measures are interrelated and mortality is determined by incidence and survival. It is thus important to interpret all three measures in combination in order to interpret overall progress in cancer prevention and control. Data from US Surveillance, Epidemiology, and End Results (SEER) programme showed a continuous increase incidence of NHL during 1975-2011, but the mortality started to decline in $1997 .^{40}$ This is also reflected in the present study (table 7): female NHL mortality started to decline in 1999, although incidence increased until 2001, while male NHL mortality started to decline in 1998, although the incidence started to level off since that year. The SEER data also showed that mortality declines for DLBCL, CLL/SLL and FL started before the decline in incidence ${ }^{61}$ indicating that the mortality reduction was most likely due to improved survival after diagnosis. We were not able to test the time trends in mortality for NHL subtypes as our data do not contain subtype-specific death cause information.

\section{STRENGTHS AND LIMITATIONS}

We conducted a comprehensive analysis of incidence, mortality and survival using 30-year cancer registry and vital statistics data. Compared with the unbiased Pohar Perme method, the age-standardised Ederer II method generates a more precise estimate for a longer term follow- up. ${ }^{64}$ Age-period-cohort (APC) effects were estimated based on continuous variables rather than commonly used 5-year or 10-year intervals. ${ }^{30}$ We have tested the time trend in 5-year age-standardised relative survival using Poisson regression-based period analysis. ${ }^{35} 36$ Findings from this study, which is based on a high-quality population-based cancer registration data, could be generalised to other provinces in Canada and other areas with a similar socioeconomic development level and a publicly funded healthcare system. The analysis has a few limitations. Reporting delay, ${ }^{65}$ the time elapsed before a diagnosed cancer case is reported to a cancer registry, was not used to adjust for incidence rate calculations as delay adjustment data are not available for this population. The delay primarily affects the estimation of incidence rates in the most recent 1-3 years (2011-2013 in this case), and the actual incidence rates in these years might have been underestimated. There have been many changes to lymphoma subtype classification, and this might have influenced the trends in incidence of subtypes with low classification reliability (eg, T/NK (natural killer) cell lymphoma) ${ }^{66}$ Relative survival is widely used to measure net survival, that is, cancer survival in the absence of other causes of death. However, approximately $50 \%-70 \%$ of patients with HL and $35 \%$ of patients with NHL died of competing causes (ie, cancers other than lymphoma and diseases of circulatory system). ${ }^{6768}$ We do not have data on treatment modalities and most prognostic factors (eg, clinical stage, serum lactate dehydrogenase (LDH) and performance status). As mentioned above, mortality rates were calculated for total HL and total NHL but subtypes. Time trends in incidence and relative survival were examined for the four most common NHL subtypes but not others.

\section{CONCLUSION}

We have examined the time trends in lymphoma incidence, survival and mortality simultaneously. In summary, the trends were overall consistent with those previously reported in Europe and USA, although there were differences when the analyses were conducted by sex and age groups and for specific subtypes. The present study has also identified the effects of age, cohort and period on lymphomas, in particular on NHL incidence. However, those effects were not able to fully explain the incidence increase prior to mid-1990s or late-1990s. The improvement in survival and the reduction in mortality were largely due to lymphoma treatment advances.

Acknowledgements The authors acknowledge the Manitoba Centre for Health Policy for use of data contained in the Population Health Research Data Repository under project 2015-028 (HIPC 2015/2016-04). The results and conclusions are those of the authors and no official endorsement by the Manitoba Centre for Health Policy, Manitoba Health, Healthy Living and Seniors, or other data providers is intended or should be inferred.

Contributors $X Y$ designed the study, analysed the data and prepared the first draft of the manuscript. SM, JJ and PS participated in designing the study, data interpretation and manuscript preparation. LL contributed to analytical methods and reviewed the manuscript.

Competing interests SM has received unrestricted research grants from GlaxoSmithKline, Sanofi Pasteur and Pfizer for unrelated studies. SM is a Canada Research Chair in Pharmacoepidemiology and Vaccine Evaluation. PS has participated in Advisory Boards for Roche, Seattle Genetics, Lundbeck, Gilead and Celgene. Other authors have no conflict of interest.

Provenance and peer review Not commissioned; externally peer reviewed.

Data sharing statement Data sharing is not applicable to this article as no data sets were generated or analysed during the current study. The data that support the findings of this study are available from the Manitoba Centre for Health Policy, but restrictions apply to the availability of these data, which were used under licence for the current study, and so are not publicly available. Data are, however, available from the authors upon reasonable request and with permission from the Manitoba Centre for Health Policy.

Open Access This is an Open Access article distributed in accordance with the Creative Commons Attribution Non Commercial (CC BY-NC 4.0) license, which permits others to distribute, remix, adapt, build upon this work non-commercially, and license their derivative works on different terms, provided the original work is properly cited and the use is non-commercial. See: http://creativecommons.org/ licenses/by-nc/4.0/

(C) Article author(s) (or their employer(s) unless otherwise stated in the text of the article) 2017. All rights reserved. No commercial use is permitted unless otherwise expressly granted.

\section{REFERENCES}

1. Liu S, Semenciw R, Mao Y, Liui S, Semenciw R, Mao Y. Increasing incidence of non-Hodgkin's lymphoma in Canada, 1970-1996: ageperiod-cohort analysis. Hematol Oncol 2003;21:57-66. 
2. Bosetti C, Levi F, Ferlay J, et al. Incidence and mortality from nonHodgkin lymphoma in Europe: the end of an epidemic? Int $J$ Cancer 2008;123:1917-23 http://www.scopus.com/inward/record.url?e id $=2-\mathrm{s} 2.0-51949104939 \&$ partnerlD $=40 \& \mathrm{md} 5=4 \mathrm{~d} 952 \mathrm{c} 3 \mathrm{bb} 81321$ 10887ab6336e38b250.

3. Clarke CA, Glaser SL. Changing incidence of non-Hodgkin lymphomas in the United States. Cancer 2002;94:2015-23.

4. Morgan G, Vornanen M, Puitinen J, et al. Changing trends in the incidence of non-Hodgkin's lymphoma in Europe. Annals of Oncology. 1997;8:S49-S54 http://www.scopus.com/inward/record. url?eid=2-s2.0-0030853011\&partnerlD=tZOtx3y1

5. Bao PP, Zheng Y, Wu CX, C-x W, et al. Cancer incidence in Urban Shanghai, 1973-2010: an updated trend and age-period-cohort effects. BMC Cancer 2016;16:284.

6. Sandin S, Hjalgrim H, Glimelius B, et al. Incidence of non-Hodgkin's lymphoma in Sweden, Denmark, and Finland from 1960 through 2003: an epidemic that was. Cancer Epidemiol Biomarkers Prev 2006;15:1295-300.

7. Karim-Kos HE, de Vries E, Soerjomataram I, et al. Recent trends of Cancer in Europe: a combined approach of incidence, survival and mortality for 17 Cancer sites since the 1990s. Eur J Cancer 2008;44:1345-89.

8. Sant M, Allemani C, Tereanu C, et al. Incidence of hematologic malignancies in Europe by morphologic subtype: results of the HAEMACARE project. Blood 2010;116:3724-34.

9. Morton LM, Wang SS, Devesa SS, et al. Lymphoma incidence patterns by WHO subtype in the United States, 1992-2001. Blood 2006;107:265-76.

10. Shenoy P, Maggioncalda A, Malik N, et al. Incidence patterns and outcomes for hodgkin lymphoma patients in the United States. Adv Hematol 2011;2011:725219.

11. Chatenoud L, Bertuccio P, Bosetti C, et al. Hodgkin's lymphoma mortality in the Americas, 1997-2008: achievements and persistent inadequacies. Int J Cancer 2013;133:687-94.

12. Levi F, La Vecchia C, Lucchini F, et al. Mortality from Hodgkin's disease and other lymphomas in Europe, 1960-1990. Oncology 1995;52:93-6.

13. Levi $F$, Lucchini $F$, Negri $E$, et al. Trends in mortality from nonHodgkin' s lymphomas. J Cancer2002;26:903-8.

14. Saika K, Zhang M. Comparison of time trends in non-Hodgkin's lymphoma mortality (1990-2006) between countries based on the WHO mortality database. Jpn J Clin Oncol 2011;41:154-5.

15. Ederer F, Axtell LM, Cutler SJ. The relative survival rate: a statistical methodology. Natl Cancer Inst Monogr 1961;6:101-20.

16. Sarfati D, Blakely T, Pearce N. Measuring Cancer survival in populations: relative survival vs cancer-specific survival. Int $J$ Epidemiol 2010;39:598-610.

17. Han X, Kilfoy B, Zheng T, et al. Lymphoma survival patterns by WHO subtype in the United States, 1973-2003. Cancer Causes Control 2008;19:841-58.

18. Marcos-Gragera R, Allemani $\mathrm{C}$, Tereanu $\mathrm{C}$, et al. Survival of european patients diagnosed with lymphoid neoplasms in 2000-2002: results of the HAEMACARE project. Haematologica 2011;96:720-8.

19. Favier $O$, Heutte $N$, Stamatoullas-Bastard $A$, et al. Survival after hodgkin lymphoma. Cancer 2009;115:1680-91.

20. Ellison LF, Wilkins K. An update on Cancer survival. Health Rep 2010;21:55-60.

21. Sant M, Allemani C, De Angelis R, De AR, et al. Influence of morphology on survival for non-Hodgkin lymphoma in Europe and the United States. Eur J Cancer 2008;44:579-87.

22. Redaniel MT, Laudico A, Mirasol-Lumague MR, et al. Geographic and ethnic differences in childhood leukaemia and lymphoma survival: comparisons of philippine residents, asian Americans and Caucasians in the United States. Br J Cancer 2010;103:149-54.

23. Pulte D, Jansen L, Gondos A, et al. Survival of patients with nonHodgkin lymphoma in Germany in the early 21st century. Leuk Lymphoma 2013;54:979-85.

24. van de Schans SA, Gondos A, van Spronsen DJ, et al. Improving relative survival, but large remaining differences in survival for nonHodgkin's lymphoma across Europe and the United States from 1990 to 2004. J Clin Oncol 2011;29:192-9.

25. Copeland G, Lake A, Firth R, et al. Cancer in North America: 20062010 Volume One: Combined Cancer Incidence for the United States, Canada and North America: NAACCR, 2013.

26. Organization WH. International classification of diseases for oncology. 3rd Edition, 2000.

27. Campo E, Swerdlow SH, Harris NL, et al. The 2008 WHO classification of lymphoid neoplasms and beyond: evolving concepts and practical applications. Blood 2011;117:5019-32.

28. Brownell M, Martens P, Kozyrskyj A, et al. Assessing the health of children in Manitoba: a Population-Based study, 2001.
29. Kim HJ, Fay MP, Feuer EJ, et al. Permutation tests for joinpoint regression with applications to Cancer rates. Stat Med 20001998;19:335-51;19:335-51.

30. Carstensen B. Age-period-cohort models for the Lexis diagram. Stat Med 2007;26:3018-45.

31. Brenner H, Gefeller O, Hakulinen T. Period analysis for 'up-to-date' cancer survival data: theory, empirical evaluation, computational realisation and applications. Eur J Cancer 2004;40:326-35.

32. Ederer $\mathrm{F}$, Heise $\mathrm{H}$. Instructions to IBM 650 programmers in processing survival computations. Bathseda,MD: National Cancer Institute, 1959

33. Corazziari I, Quinn M, Capocaccia R. Standard Cancer patient population for age standardising survival ratios. Eur $\mathrm{J}$ Cancer 2004;40:2307-16.

34. Swaminathan R, Brenner H. Stastistical methods for Cancer survival analysis. IARC Sci Pub/ 2011;162:7-13 https://www.scopus.com/ inward/record. uri?eid=2-s2.0-79959804512\&partnerID=40\&md5= ca4939ecbb2b896881fb5d923b4b847e.

35. Holleczek B, Gondos A, Brenner H. periodR - an R package to calculate long-term Cancer survival estimates using period analysis. Methods Inf Med 2009;48:123-8.

36. Holleczek B, Brenner H. Model based period analysis of absolute and relative survival with $\mathrm{R}$ : data preparation, model fitting and derivation of survival estimates. Comput Methods Programs Biomed 2013:110:192-202

37. Brenner $\mathrm{H}$, Hakulinen T. Up-to-date and precise estimates of Cancer patient survival: model-based period analysis. Am J Epidemiol 2006;164:689-96.

38. Adamson P, Bray F, Costantini AS, et al. Time trends in the registration of Hodgkin and non-Hodgkin lymphomas in Europe. Eur $J$ Cancer 2007;43:391-401.

39. van de Schans SA, Issa DE, Visser O, et al. Diverging trends in incidence and mortality, and improved survival of nonHodgkin's lymphoma, in the Netherlands, 1989-2007. Ann Oncol 2012;23:171-82.

40. Howlader N, Noone AM, Krapcho M, et al. SEER Cancer statistics review, 1975-2013. Bethesda, MD: National Cancer Institute, 2016. http://seer.cancer.gov/csr/1975_2013/

41. Call TG, Norman AD, Hanson CA, et al. Incidence of chronic lymphocytic leukemia and high-count monoclonal B-cell lymphocytosis using the 2008 guidelines. Cancer 2014;120:2000-5.

42. Chihara $\mathrm{D}$, Ito $\mathrm{H}$, Matsuda $\mathrm{T}$, et al. Differences in incidence and trends of haematological malignancies in Japan and the United States. Br J Haematol 2014;164:536-45.

43. Ekström-Smedby K. Epidemiology and etiology of non-Hodgkin lymphoma--a review. Acta Oncol 2006;45:258-71.

44. Gobbi PG, Ferreri AJ, Ponzoni M, et al. Hodgkin lymphoma. Crit Rev Oncol Hematol 2013;85:216-37.

45. Liu S, Semenciw R, Mao Y. Increasing incidence of non-Hodgkin's lymphoma in Canada, 1970-1996: age-period-cohort analysis. Hematol Oncol 2003;21:57-66.

46. Viel J-F, Fournier E, Danzon A. Age-period-cohort modelling of nonHodgkin's lymphoma incidence in a French region: A period effect compatible with an environmental exposure. Environ Heal A Glob Access Sci Source $20101 \mathrm{http} / / /$ www.scopus.com/inward/record. url?eid=2-s2.0-77955185183\&partner $\mid \mathrm{D}=40 \& \mathrm{md} 5=1$ fee $6402 \mathrm{e} 2 \mathrm{fffe}$ $72 \mathrm{~b} 404730 \mathrm{~b} 0$ dadfa8d.

47. Poll M, Moreno C, Vergara A, et al. Incidence of Non-Hodgkin's Period of Diagnosis Lymphoma and Cohort in Spain : Effects' Analysis of. Cancer Epidemiol Biomarkers Prev 1998;7:621-5.

48. Glaser SL, Clarke CA, Keegan TH, et al. Time Trends in Rates of Hodgkin Lymphoma histologic subtypes: true incidence changes or evolving diagnostic practice? Cancer Epidemiol Biomarkers Prev 2015;24:1474-88.

49. Seftel MD, Demers AA, Banerji V, et al. High incidence of chronic lymphocytic leukemia (CLL) diagnosed by immunophenotyping: a population-based canadian cohort. Leuk Res 2009;33:1463-8.

50. Hartge P, Devesa SS. Quantification of the impact of known risk factors on time trends in non-Hodgkin's lymphoma incidence. Cancer Res 1992;52:5566s-9.

51. Lim RB, Loy EY, Lim GH, et al. Gender and ethnic differences in incidence and survival of lymphoid neoplasm subtypes in an asian population: secular trends of a population-based Cancer registry from 1998 to 2012. Int J Cancer 2015;137:2674-87. 2015.

52. Ellison LF. Differences in Cancer survival in Canada by sex. Health Rep 2016;27:19-28.

53. Sjöberg J, Halthur C, Kristinsson SY, et al. Progress in Hodgkin lymphoma: a population-based study on patients diagnosed in Sweden from 1973-2009. Blood 2012;119:990-6. 
54. Pulte D, Jansen L, Castro FA, et al. Changes in the survival of older patients with hematologic malignancies in the early 21 st century. Cancer 2016;122:2031-40.

55. van de Schans SA, Gondos A, van Spronsen DJ, et al. Improving relative survival, but large remaining differences in survival for nonHodgkin's lymphoma across Europe and the United States from 1990 to 2004. J Clin Oncol 2011;29:192-9.

56. Rathore B, Kadin ME. Hodgkin's lymphoma therapy: past, present, and future. Expert Opin Pharmacother 2010;11:2891-906.

57. Sant M, Minicozzi P, Mounier M, et al. Survival for haematological malignancies in Europe between 1997 and 2008 by region and age: results of EUROCARE-5, a population-based study. Lancet Oncol 2014:15:931-42.

58. Younes A, Gopal AK, Smith SE, et al. Results of a pivotal phase II study of brentuximab vedotin for patients with relapsed or refractory Hodgkin's lymphoma. J Clin Oncol 2012;30:2183-9.

59. Katanoda K, Saika K. Comparison of time trends in multiple myeloma mortality (1990-2006) between countries based on the WHO mortality database. Jpn J Clin Oncol 2011;41:444-5.

60. Levi F, Lucchini F, Negri E, et al. Trends in mortality from nonHodgkin's lymphomas. Leuk Res 2002;26:903-8.

61. Howlader N, Morton LM, Feuer EJ, et al. Contributions of subtypes of Non-Hodgkin Lymphoma to Mortality Trends. Cancer Epidemiol Biomarkers Prev 2016;25:174-9.
62. Bosetti C, Levi F, Ferlay $\mathrm{J}$, et al. The recent decline in mortality from hodgkin lymphomas in central and eastern Europe. Ann Oncol 2009;20:767-74.

63. Pastor-Barriuso R, López-Abente G. Changes in period and cohort effects on haematological Cancer mortality in Spain, 1952-2006. BMC Cancer 2014;14:250.

64. Lambert PC, Dickman PW, Rutherford MJ. Comparison of different approaches to estimating age standardized net survival. BMC Med Res Methodol 2015;15:64.

65. Clegg LX, Feuer EJ, Midthune DN, et al. Impact of reporting delay and reporting error on Cancer incidence rates and trends. $J$ Natl Cancer Inst 2002;94:1537-45.

66. Clarke CA, Undurraga DM, Harasty PJ, et al. Changes in Cancer registry coding for lymphoma subtypes: reliability over time and relevance for surveillance and study. Cancer Epidemiol Biomarkers Prev 2006;15:630-8.

67. Bluhm EC, Ronckers C, Hayashi RJ, et al. Cause-specific mortality and second Cancer incidence after non-Hodgkin lymphoma: a report from the Childhood Cancer survivor Study. Blood 2008;111:4014-21.

68. Castellino SM, Geiger AM, Mertens AC, et al. Morbidity and mortality in long-term survivors of hodgkin lymphoma: a report from the Childhood Cancer survivor Study. Blood 2011:117:1806-16. 